\title{
Dynamics of Glycine Receptor Insertion in the Neuronal Plasma Membrane
}

\author{
Madelaine Rosenberg, Jochen Meier, Antoine Triller, and Christian Vannier \\ Laboratoire de Biologie Cellulaire de la Synapse Normale et Pathologique, Institut National de la Santé et de la Recherche \\ Médicale U497, Ecole Normale Supérieure, 75005 Paris, France
}

The exocytosis site of newly synthesized glycine receptor was defined by means of a morphological assay to characterize its export from the trans-Golgi Network to the plasma membrane. This was achieved by expressing in transfected neurons an $\alpha 1$ subunit bearing an $\mathrm{N}$-terminal tag selectively cleavable from outside the cell by thrombin. This was combined with a transient temperature-induced block of exocytic transport that creates a synchronized exocytic wave. Immunofluorescence microscopy analysis of the cell surface appearance of newly synthesized receptor revealed that exocytosis mainly occurred at nonsynaptic sites in the cell body and the initial portion of dendrites. At the time of cell surface insertion, the receptors existed as discrete clusters. Quantitative analysis showed that glycine receptor clusters are stable in size and subsequently appeared in more distal dendritic regions. This localization resulted from diffusion in the plasma membrane and not from exocytosis of transport vesicles directed to dendrites. Kinetic analysis established a direct substrate-product relationship between pools of somatic and dendritic receptors. This indicated that clusters represent intermediates between newly synthesized and synaptic receptors. These results support a diffusionretention model for the formation of receptor-enriched postsynaptic domains and not that of a vectorial intracellular targeting to synapses.

Key words: glycine receptor; synapse; spinal cord neuron; exocytosis; diffusion/retention; transfection
Signal transmission between neurons relies on a precise distribution of ion channels and neurotransmitter receptors within distinct plasma membrane domains over axonal and dendritic compartments. In this respect, synapses represent highly organized structures in which complex assemblies of transmembrane and cytoplasmic proteins enable communication between presynaptic and postsynaptic cells. As highlighted for central excitatory synapses, numerous interactions within these complexes regulate receptor localization by mediating their clustering and/or anchoring to cytoskeleton (Fanning and Anderson, 1999; Kim and Huganir, 1999; Garner et al., 2000).

In inhibitory synapses, similar mechanisms operate to localize glycine receptors (GlyRs) and $\mathrm{GABA}_{\mathrm{A}}$ receptors $\left(\mathrm{GABA}_{\mathrm{A}} \mathrm{Rs}\right)$. GlyR was the first CNS neurotransmitter receptor shown to accumulate in postsynaptic membrane areas coextending with patches of the cytoplasmic tubulin-binding protein gephyrin (Triller et al., 1985, 1987; Kirsch et al., 1991; Vannier and Triller, 1997; Colin et al., 1998). Gephyrin, which also binds the GlyR $\beta$ subunit (Meyer et al., 1995), is required for tethering GlyR as clusters within postsynaptic loci (Kirsch et al., 1993; Feng et al., 1998). Although direct binding to $\mathrm{GABA}_{\mathrm{A}} \mathrm{R}$ has not been dem-

\footnotetext{
Received Feb. 22, 2001; revised April 25, 2001; accepted April 30, 2001.

This work was supported by grants from the Institut de Recherche sur la Moelle Epinière. M.R. was supported by Institut National de la Santé et de la Recherche Médicale and the Medical Research Council of Canada. J.M. was supported by fellowships from Fonds der Chemischen Industrie (0653082), Deutscher Akademischer Austauschdienst (D/98/03816), and Centre International des Etudiants et Stagiaires (242708G).We thank Drs. B. Dargent and D. Choquet for helpful comments and criticism and for reading this manuscript. We thank the Vector Core of the University Hospital of Nantes supported by the Association Française contre les Myopathies for providing the Ad.RSV.nlsLacZ.

Correspondence should be addressed to Christian Vannier, Laboratoire de Biologie Cellulaire de la Synapse Normale et Pathologique, Institut National de la Santé et de la Recherche Médicale U497, Ecole Normale Supérieure, 46 rue d’Ulm, 75005 Paris, France. E-mail: vannier@wotan.ens.fr.

Copyright (c) 2001 Society for Neuroscience $0270-6474 / 01 / 215036-09 \$ 15.00 / 0$
}

onstrated, gephyrin also mediates synaptic clustering of $\mathrm{GABA}_{\mathrm{A}} \mathrm{R} \alpha 2$ and $\gamma 2$ subunits (Essrich et al., 1998; Kneussel et al., 1999; Lévi et al., 1999).

It is not known how postsynaptic proteins, and among them neurotransmitter receptors, are delivered to their appropriate domain in the plasma membrane. So far, investigations on the formation of compartments in neurons have mainly been focused on sorting events in the acquisition of cell polarity (Winckler and Mellman, 1999). They suggested that direct vesicular pathways exist for segregation of several proteins in the dendritic plasma membrane (de Hoop et al., 1995; Jareb and Banker, 1998; Stowell and Craig, 1999). In contrast, axonal targeting, which also uses vesicular pathways, may rely on an additional selective sorting event, operating downstream of transport (Burack et al., 2000). The mosaic-like organization of the neuronal surface adds another complexity level and raises questions as to how selective postsynaptic receptor accumulation is achieved in dendrites. In particular, it remains to be explored whether receptor exocytosis is directed and synapse-specific or occurs randomly before receptor-specific retention in synapses (Craig et al., 1994).

In previous work using neurons expressing various GlyR subunits, we showed that formation of receptor clusters precedes their gephyrin-mediated stabilization in synaptic loci (Meier et al., 2000). Here, we determined the transport route of newly synthesized GlyR in transfected neurons. We used a GlyR $\alpha 1$ subunit bearing an N-terminal tag selectively cleavable from outside the cell by thrombin. This allowed the selective detection of intracellular or cell surface receptor. A nearly synchronized transport of GlyR to the cell surface was obtained with a temperature-induced block of trans Golgi Network (TGN) exit. With these tools, we show that: (1) GlyR clusters are formed after plasma membrane insertion, (2) GlyR exocytosis is not directed and synapse-specific, and (3) GlyR exocytosis occurs predomi- 
A

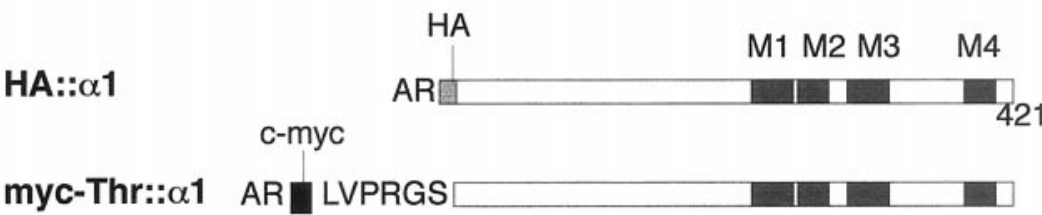

B
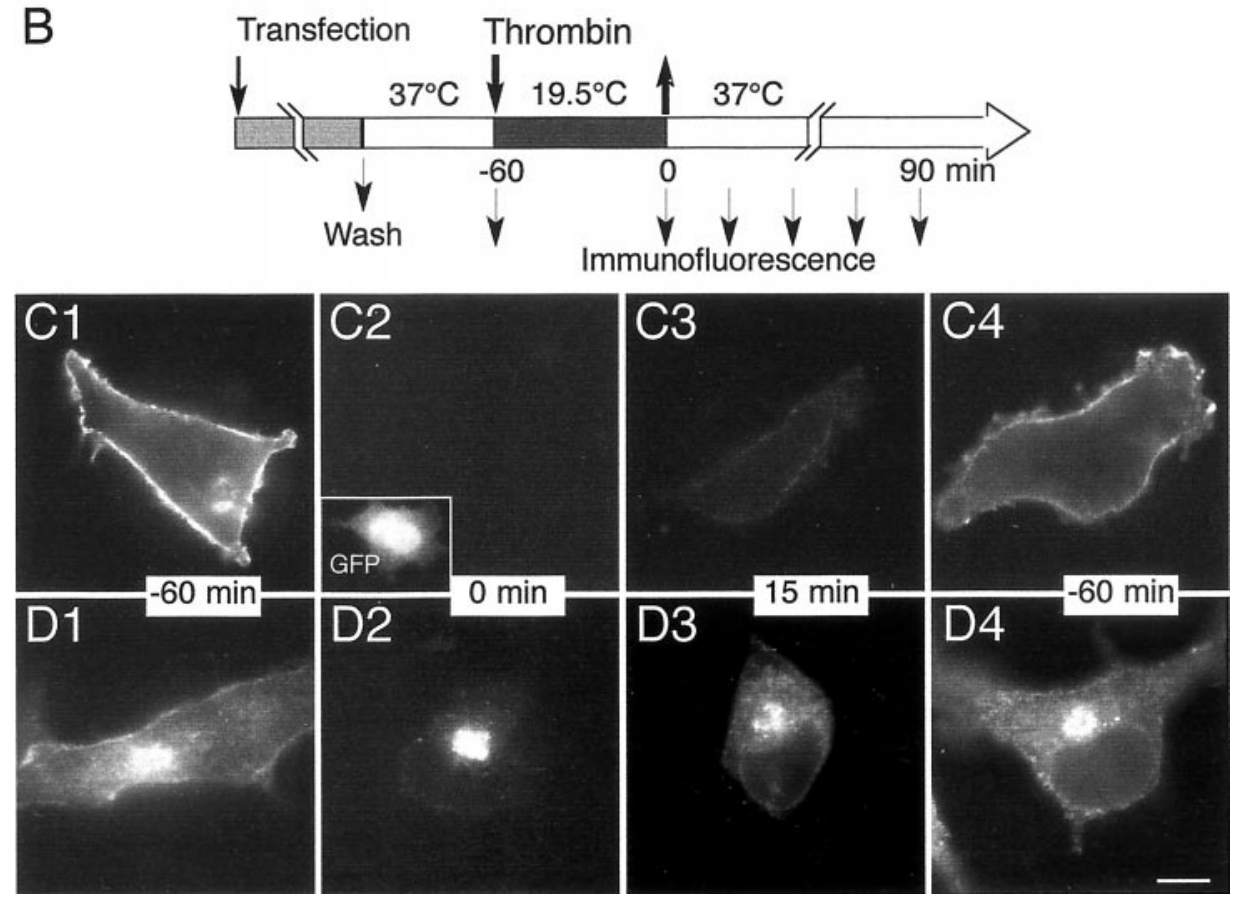

Figure 1. Structure of GlyR constructs and strategy for cell surface tag cleavage. A, Diagram of the structures of the tagged forms of $\alpha 1$ subunit. The gray and black boxes are the HA and c-myc sequences, respectively, introduced after the indicated $\mathrm{N}$-terminal amino acid residues. Hatched boxes represent the four transmembrane domains, M1-M4. In the myc-Thr:: $\alpha 1$ construct, the thrombin cleavage sequence is shown between the myc and polypeptide sequences. $B$, Temporal sequence of the temperature-induced block of TGN exit, thrombin digestion of extracytoplasmic receptor, and surface recovery. The rod is the temporal axis and represents the treatments, with the indication of their temperature and duration. The thick arrows indicate the time of thrombin addition and withdrawal, to and from the culture medium. Small arrows in the restoration phase indicate time points at which cells are fixed and processed for immunofluorescence staining. When required, a second thrombin digestion could be performed at these times before fixation. C1-D4, Validation of the strategy for cell surface myc tag cleavage in COS-7 cells. Cells were cotransfected with pC-myc-Thr:: $\alpha 1$ and pEGFP-N1 and processed according to the protocol depicted in Figure $1 B$. The c-myc epitope was revealed by immunostaining (see Materials and Methods) on living nonpermeabilized cells before fixation $(C)$ or on cells subjected to a second thrombin treatment before fixation and permeabilization $(D)$. Cells were analyzed at $-60 \mathrm{~min}$ (control cells, $C 1$, $D 1)$, or at $0(C 2, D 2), 15(C 3, D 3)$, and $60 \mathrm{~min}$ $(C 4, D 4)$ of the restoration phase. The inset in $C 2$ shows the GFP fluorescence used to identify the transfected cell. Scale bar, $10 \mu \mathrm{m}$. nantly at extrasynaptic sites in the soma and initial portions of dendrites, and clusters subsequently diff use to the distal dendritic plasma membrane before postsynaptic retention.

\section{MATERIALS AND METHODS}

DNA constructs. The GlyR $\alpha 1$ subunit cDNA was modified as described (Meier et al., 2000) by inserting between the second and third amino acids of the mature protein the sequences encoding either the EQKLI SEEDL peptide from c-myc or the YPYDVPDYA peptide from hemagglutinin (HA), yielding myc:: $\alpha 1$ and HA:: $\alpha 1$, respectively. The thrombin cleavage sequence LVPRGS was introduced immediately after the c-myc sequence in myc:: $\alpha 1$ by site-directed mutagenesis (GeneEditor system; Promega, Charbonnières, France) using the oligonucleotide 5' TCT GAG GAG GAT CTA-GTA-CCC-CGA-GGA TCT GCA CCC AAG CCT 3 '. This resulted in the final EQKLISEEDLVPRGS sequence, yielding myc-Thr:: $\alpha 1$. cDNA constructs were subcloned in the eukaryotic expression vector derived from pEGFP-N1 (after removal of EGFP coding sequence; Clontech, Palo Alto, CA) allowing a cytomegalovirus promoter-driven expression. This yielded plasmids $\mathrm{pC}$-myc:: $\alpha 1$, pC-HA:: $\alpha 1$, and $\mathrm{pC}$-myc-Thr:: $\alpha 1$, respectively. All cDNAs were verified by dideoxy sequencing, and all plasmids were prepared by anionexchange chromatography (resin from Qiagen S.A., France).

Cell culture and transient transfections. Spinal cord neurons from Sprague Dawley rats were prepared at day 14 of gestation, or embryonic day 14 (E14), as previously described (Meier et al., 2000). Routinely, they were plated at a density of $7.5 \times 10^{-4}$ cells $/ \mathrm{cm}^{2}$ onto glass coverslips (12 $\mathrm{mm}$ diameter) coated with $15 \mu \mathrm{g} / \mathrm{ml}$ poly-DL-ornithine (Sigma, St. Louis, MO) in $16 \mathrm{~mm}$ wells. After the neurons had attached, coverslips were transferred (cell-side down) to dishes containing a confluent layer of glial cells. They were then cultured for up to $9 \mathrm{~d}$, in a $5 \% \mathrm{CO}_{2}$ atmosphere at $37^{\circ} \mathrm{C}$. Glial cell suspensions obtained at E14 were plated at a density of $4 \times 10^{-4}$ cells $/ \mathrm{cm}^{2}$ in $35 \mathrm{~mm}$ dishes coated with $15 \mu \mathrm{g} / \mathrm{ml}$ poly-DLornithine and grown for 2 weeks to confluence in complete L15 culture medium) supplemented with $10 \%$ horse serum (Life Technologies,
Gaithersburg, $\mathrm{MD}$ ), at $37^{\circ} \mathrm{C}$ and $5 \% \mathrm{CO}_{2}$. Culture medium was changed after $7 \mathrm{~d}$. The day before neuron plating, glial cells were transferred to serum-free Neurobasal medium supplemented with B27 (Life Technologies) (Brewer et al., 1993). Transfection of neurons was performed 6-8 $\mathrm{d}$ after plating by polyethylenimine (PEI) adenofection as previously described (Meier et al., 2000.) Briefly, neurons on coverslips were transferred to $16 \mathrm{~mm}$ wells containing $300 \mu \mathrm{l}$ of fresh serum-free Neurobasal medium, supplemented with $0.25 \mathrm{~mm}$ L-glutamine (Life Technologies) equilibrated at $37^{\circ} \mathrm{C}$ and $7.5 \% \mathrm{CO}_{2}$. For one well, $300 \mathrm{ng}$ of DNA was complexed in $0.15 \mathrm{M} \mathrm{NaCl}$ with PEI ( $800 \mathrm{kDa}$; Fluka, Neu-Ulm, Germany; molar charge ratio $\mathrm{r}^{+/-}=3$ ) and $2.25 \times 10^{-7}$ pfu of adenovirus (replication-deficient, Ad-RSV-nlsLacZ). After a $2 \mathrm{hr}$ incubation with the complex, the neurons were returned to the glial cell monolayer for exogene expression for up to $24 \mathrm{hr}$. In cotransfection experiments, a plasmid molar ratio pC-myc-Thr:: $\alpha 1 / \mathrm{pC}-\mathrm{HA}:: \alpha 1$, or pC-myc-Thr:: $\alpha 1 / \mathrm{pEGFP}-\mathrm{N} 1$ of 1 was used.

African green monkey kidney (COS-7) cells were plated on glass coverslips and grown in DMEM (Life Technologies) containing 10\% fetal calf serum (FCS; Life Technologies) at $37^{\circ} \mathrm{C}$ and $7.5 \% \mathrm{CO}_{2}$. For transfection, experiments were performed on subconfluent cultures $(60 \%$ confluency) using the DEAE-Dextran method. Usually, $2 \mu \mathrm{g}$ of plasmid DNA was added to $35 \mathrm{~mm}$ dishes. Transient protein expression was allowed to proceed for $24 \mathrm{hr}$ at $37^{\circ} \mathrm{C}$ and $7.5 \% \mathrm{CO}_{2}$.

Thrombin treatment of transfected cells. Cleavage of the c-myc tag from the cell surface myc-Thr:: $\alpha 1$ GlyR subunit was performed as follows: after 14-16 hr of exogene expression, transfected cells were washed twice with air-equilibrated minimal essential medium (MEM; Life Technologies) supplemented with $10 \mathrm{~mm}$ HEPES, $4 \mathrm{~mm} \mathrm{NaHCO}_{3}, 20 \mathrm{~mm}$ glucose, $2 \mathrm{~mm}$ glutamine, $0.11 \mathrm{mg} / \mathrm{ml}$ pyruvate, and $1 \mathrm{mg} / \mathrm{ml}$ chicken egg albumin (Sigma). The cells were then incubated at $19.5^{\circ} \mathrm{C}$ for $1 \mathrm{hr}$ in the same medium containing $2.5 \mathrm{U} / \mathrm{ml}$ of thrombin (Roche Diagnostics). Cells were then washed in the same medium without thrombin and returned to their initial culture medium at $37^{\circ} \mathrm{C}$ (restoration phase) (Fig. 1) for the indicated time period. When required, cells were subjected after a 
restoration phase to a second thrombin treatment at $4^{\circ} \mathrm{C}$ before fixation. In this case, only intracellular tags remained on the GlyR subunit. These various incubation periods affected neither cell viability nor expression of endogenous GlyR or gephyrin and did not alter the TGN-38 perinuclear localization (data not shown).

Immunofluorescence labeling. Immunofluorescence labeling was performed essentially as described (Meier et al., 2000). Extracytoplasmic epitope tags were detected before fixation by incubating living cells for 30 min at $4^{\circ} \mathrm{C}$ with primary antibodies diluted in air-equilibrated MEM medium supplemented with $20 \mathrm{~mm}$ glucose and $1 \mathrm{mg} / \mathrm{ml} \mathrm{BSA}$. After three washes in the same medium, cells were fixed and processed as described below. Intracellular epitope tags were detected during the restoration phase in cells first treated with thrombin and then fixed and permeabilized, before incubation with the primary antibodies.

COS-7 cells were fixed in 4\% (w/v) paraformaldehyde in PBS for 15 min. Neurons were first fixed in $2 \%$ paraformaldehyde and $4 \%$ sucrose in PBS for 5 min and then in $4 \%$ paraformaldehyde and $4 \%$ sucrose in PBS for 15 min. Cells were rinsed with $\mathrm{PBS}$, quenched with $50 \mathrm{mM} \mathrm{NH}_{4} \mathrm{Cl}$ in $\mathrm{PBS}$, and then when required, permeabilized with $\mathrm{PBS}$ containing $0.12 \%$ $(\mathrm{w} / \mathrm{v})$ Triton X-100 and $0.12 \%(\mathrm{w} / \mathrm{v})$ gelatin for $4 \mathrm{~min}$. To prevent nonspecific labeling, cells were blocked with $0.25 \%(\mathrm{w} / \mathrm{v})$ in PBS for $1 \mathrm{hr}$. They were then incubated ( $1 \mathrm{hr}$ at room temperature) with primary antibodies in PBS containing $0.12 \%(w / v)$ gelatin. After five washes (5 min each) with the same buffer, the appropriate secondary antibodies were reacted for $45 \mathrm{~min}$. After four washes, cells were mounted in Vectashield (Vector Laboratories, Burlingame, CA). Observations were made using the $63 \times / 1.32$ objective of a Leica (Nussloch, Germany) DMR fluorescence microscope. Green fluorescent protein (GFP) was detected using an FITC filter set.

The primary antibodies were used at the following concentrations: mouse anti-gephyrin monoclonal antibody (mAb7a), $0.4 \mu \mathrm{g} / \mathrm{ml}$ (Pfeiffer et al., 1984; Roche Diagnostics); mouse anti-c-myc monoclonal antibody, $1 \mu \mathrm{g} / \mathrm{ml}$ (clone 9E10; Roche Diagnostics); rabbit anti-c-myc polyclonal antibody, $2 \mu \mathrm{g} / \mathrm{ml}$ (Upstate Biotechnology, Lake Placid, NY); rat anti-HA monoclonal antibody, $1 \mu \mathrm{g} / \mathrm{ml}$ (clone 3F10; Roche Diagnostics); and rabbit anti-vesicular inhibitory amino acid transporter antiserum, 1:200 dilution (anti-VIAAT; Dumoulin et al., 1999). Secondary antibodies were from Jackson ImmunoResearch, West Grove, PA and used at a dilution of 1:200 [fluorescein (FITC)-conjugated affinity-purified goat anti-rabbit IgG and FITC-conjugated affinity-purified goat anti-rat IgG (depleted in anti-mouse IgG activity)], or of 1:500 [carboxymethylindocyanine-3 (Cy3)-conjugated affinity-purified goat anti-mouse IgG (depleted in anti-rat IgG activity)].

Quantitative analysis. For all experiments, nonspecific labeling and the absence of antibody cross-reaction in double-labeling experiments were verified. Fluorescent images were acquired using standard epifluorescence microscopy with a Leica DMR/HCS microscope $(63 \times$ or $100 \times$ oil immersion objectives) equipped with $\mathrm{Cy} 3$ and FITC specific filters and a Hamamatsu CCD camera (C5985). GlyR clusters were quantified on digitalized images. Neurons $(8<n<30)$ from two independent cultures were analyzed. The total number of GlyR clusters in neuronal compartments was determined by counting nonoverlapping GlyR clusters in a series of images taken at different focal planes of the same cell. The number of GlyR clusters on dendrites was determined by counting the number of clusters per $5 \mu \mathrm{m}$ length of dendrite. Mean values \pm SEM were calculated using StatView F4.11 software.

\section{RESULTS}

\section{Strategy for selective visualization of proteins newly inserted in the plasma membrane}

In previous work we showed that myc-tagged GlyR $\alpha 1$ or $\alpha 2$ subunits expressed in transfected neurons are progressively incorporated into postsynaptic domains where they colocalize with gephyrin (Meier et al., 2000). These findings indicated that correct sorting of exogenous receptor could be reconstituted after neuron transfection. They also provided the experimental basis for investigation of the secretory traffic of GlyR and for determination of its insertion site in the plasma membrane of differentiating neurons. Recent data from our laboratory show that GlyR $\alpha 1$ and $\alpha 2$ subunit mRNAs are present beneath postsynaptic loci (Racca et al., 1997; Gardiol et al., 1999). This localization coupled to an eventual translation would provide a mechanism for rapid insertion of GlyR in the synaptic plasma membrane, a hypothesis that remains to be confirmed. Here, we created an $\alpha 1$ construct, myc-Thr:: $\alpha 1$, bearing a thrombin cleavage site connecting the $\mathrm{N}$-terminal myc epitope and the subunit (Fig. 1A). It was encoded by a cDNA lacking the sequence corresponding to the mRNA $3^{\prime}$ untranslated region, which is thought to be responsible in most cases for the dendritic mRNA localization (Gardiol et al., 2001, see references). Therefore its synthesis most likely occurred in the somatic endoplasmic reticulum only. This was a major advantage because protein detected at the dendritic locations could only result from synthesis in the soma followed by transport. This myc-Thr:: $\alpha 1$ construct was used with the aim of trimming cell surface c-myc epitope tags from living transfected cells to allow the selective visualization at the plasma membrane of newly synthesized receptor. After $14-16 \mathrm{hr}$ of expression, the transfected cells were incubated at $19.5^{\circ} \mathrm{C}$ for $1 \mathrm{hr}$ to synchronize the post-Golgi traffic. This lower temperature prevents exit from the TGN where secretory proteins accumulate, a treatment that has the advantage of avoiding a pharmacological perturbation of intracellular transport (Matlin and Simons, 1983; Griffiths et al., 1985). The thrombin treatment and the temperature-induced block of TGN exit were combined. They were followed by a restoration phase obtained by raising the temperature to $37^{\circ} \mathrm{C}$ for periods ranging from 0 to $90 \mathrm{~min}$ (Fig. $1 \mathrm{~B}$ ). This procedure was aimed at monitoring the fate of tagged GlyR after the reappearance of the myc epitope at the cell surface in a synchronized wave.

The recovery of cell surface expression of myc-Thr:: $\alpha 1$ in transfected COS-7 cells subjected to this protocol is illustrated in Figure $1(C 1-C 4)$. A diff use fluorescent labeling of the plasma membrane was observed when living, untreated cells were incubated with the anti-myc antibody before fixation (Fig. 1C1). This fluorescence was no longer detectable after thrombin treatment (Fig. 1C2, time 0 of the restoration phase). It was, however, progressively restored after warmup (Fig. 1C3,C4, times 15 and $60 \mathrm{~min}$ ), indicating that transport to the plasma membrane was restored after the release of the temperature block. Consistently, this was accompanied during the same period by the redistribution of the intracellular myc epitope. As shown in Figure 1D, myc-tagged subunits observed during the restoration phase after a second thrombin treatment (see Materials and Methods) migrated from the TGN located in the perinuclear region to putative transport containers radiating away toward the cell periphery (Fig. 1, compare D2, D3, D4). A residual labeling of the TGN was often observed for up to $60 \mathrm{~min}$ after transfer of the cells from 19.5 to $37^{\circ} \mathrm{C}$. Nevertheless, the overall distribution pattern, after a $60 \mathrm{~min}$ restoration phase, of the myc tag protected from thrombin cleavage was similar to that of myc-Thr:: $\alpha 1$ in untreated cells (Fig. 1, compare D1, D4). The vast majority of myc-Thr:: $\alpha 1$ inserted into the cell membrane was most likely derived from newly synthesized molecules because the c-myc epitope was barely detected outside of the TGN in blocked cells (Fig. 1D2, time 0 of the restoration phase). Together, these results show that thrombin efficiently trimmed myc-Thr:: $\alpha 1$ expressed at the cell surface and that transport of newly synthesized subunits to the cell surface can be selectively visualized.

\section{Insertion of GlyR as microclusters in the plasma membrane of neurons}

Having established the resumption of plasma membrane insertion of intact tagged GlyR after releasing the inhibition of exit from the TGN, we applied the above procedure to neurons transfected $7-9 \mathrm{~d}$ after plating. In a previous study (Meier et al., 2000, 2001) 

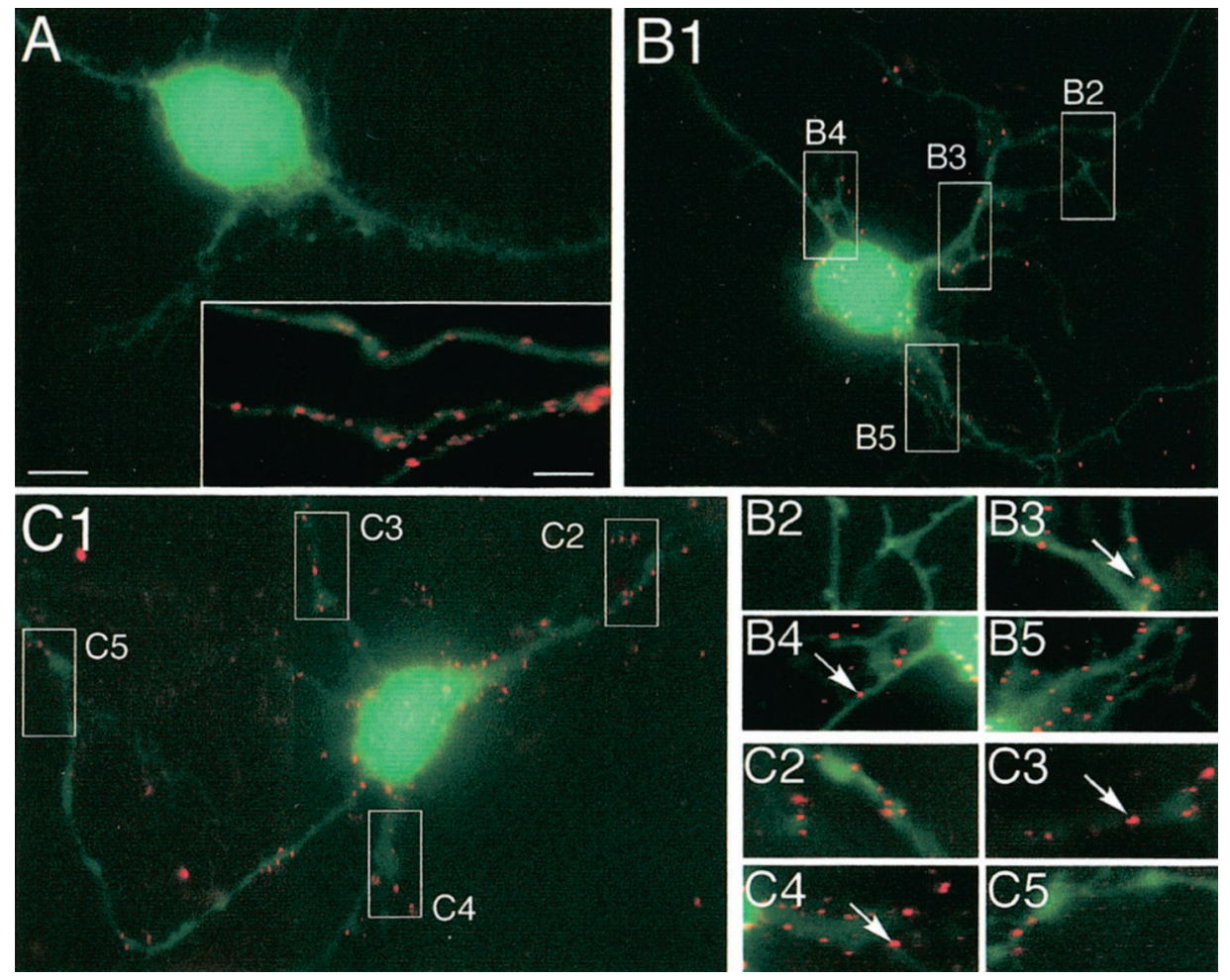

Figure 2. Cell surface GlyR clusters during the restoration phase in neurons. Neurons were cotransfected with pC-myc-Thr:: $\alpha 1$ and pEGFP-N1 and processed as described in Figure $1 C$. Cell surface c-myc immunofluorescence is shown superimposed on GFP fluorescence in treated cells fixed at $0(A), 15(B)$, and $60(C)$ min of the restoration phase. $A$, Inset, Expression of myc-Thr:: $\alpha 1$ in a control neuron $16 \mathrm{hr}$ after transfection. B2-B5, C2-C5, Higher magnification of regions outlined and numbered in $B 1, C 1$, respectively. Note the initial appearance of c-myc immunoreactivity as puncta $(B, C$, arrows) similar to those shown in the inset in $A$. Scale bars: $A, 10 \mu \mathrm{m}$; inset, $5 \mu \mathrm{m}$. we had established that, in neurons, homomeric GlyR assembled with myc-tagged subunits was expressed at the cell surface. A patchy pattern of GlyR distribution was observed when anti-myc antibody was reacted with intact living cells at low $\left(2^{\circ} \mathrm{C}\right)$ temperature without access to the cell interior (Misek et al., 1984; Pfeiffer et al., 1985) to prevent free diffusion of receptors in the membrane. It formed discrete microclusters distributed over the somatodendritic surface that could be observed as early as $4 \mathrm{hr}$ after transfection at nonsynaptic loci. With time they tended to form larger clusters associated with postsynaptic gephyrin. The formation of GlyR clusters was neuron-specific and was not observed in non-neuronal cells (COS-7) cotransfected with gephyrin and GlyR subunits unable to interact with gephyrin (Meier et al., 2000). In this case, immunolabeling of living cells expressing high levels of cell surface GlyR did not lead to receptor cluster formation, and GlyR remained diff usely distributed. We had then hypothesized that the small clusters may represent kinetic intermediates between newly cell surface-inserted and postsynaptic GlyR. The use of the myc-Thr:: $\alpha 1$ construct was now aimed at visualizing the first detectable form of GlyR at the surface of living, unfixed cells (see Materials and Methods) and its localization.

Neurons were cotransfected with pC-myc-Thr:: $\alpha 1$ and pEGFP-N1 to compare the myc tag distribution at the cell surface with the entire cell morphology outlined by GFP fluorescence. As observed for COS-7 cells, no cell surface myc tag labeling was observed after $1 \mathrm{hr}$ of thrombin treatment (Fig. $2 A$, time 0 of the restoration phase). Cell surface expression of myc-Thr:: $\alpha 1$ occurred progressively during the restoration phase (Fig. $2 B, C$ ). It could be detected as early as $7 \mathrm{~min}$ after its onset (data not shown) and, as illustrated here at 15 (Fig. 2B) and 60 (Fig. 2C) min. With time, GlyR clusters could be detected farther away on neurites. Diff use staining of the myc tag was never detected on the cell surface whatever the stages of the restoration phase. Instead, myc-Thr:: $\alpha 1$ was always seen as forming microclusters (Fig.
$2 B, C)$, similar to those observed in cells reacted with the antibody before thrombin treatment (Fig. $2 A$, inset). They were also similar to those previously observed for tagged $\alpha 1$ and $\alpha 2$ GlyR subunits lacking the thrombin cleavage site (Meier et al., 2000).

It is worth noting that during the restoration phase very little association of newly inserted GlyR with postsynaptic loci could be observed. This is illustrated in experiments (Fig. 3A, arrows) in which the myc tag was detected together with the vesicular inhibitory amino acid transporter (VIAAT), taken as a marker of inhibitory presynaptic boutons in synapses (Dumoulin et al., 1999). As shown after $30 \mathrm{~min}$ of restoration, GlyR clusters were mainly extrasynaptic (arrowheads). This extrasynaptic localization is consistent with our previous results showing that postsynaptic accumulation of transfected GlyR at inhibitory synapses was a progressive event taking place over a $24 \mathrm{hr}$ period (Meier et al., 2000). Nonsaturating expression is suggested by the fact that, in transfected neurons, we do not observe a first synaptic delivery followed by a subsequent distribution to extrasynaptic areas. This indicates that newly synthesized GlyR undergoes exocytosis mainly, if not exclusively, at nonsynaptic plasma membrane domains.

A measure of the size of plasma membrane GlyR clusters at various time points of the restoration phase for up to $90 \mathrm{~min}$ revealed a constant surface area of $\sim 0.11 \pm 0.014 \mu \mathrm{m}^{2}$ (Fig. $3 B$ ). This value is close to the steady-state size $\left(0.09 \mu \mathrm{m}^{2}\right)$ of HAtagged $\alpha 1$ clusters not associated with gephyrin in transfected neurons (Meier et al., 2000). It should be noted that this labeling pattern of clusters is not dependent on the antibody concentration reacted with the cooled, living cells [e.g., $10 \mu \mathrm{g} / \mathrm{ml}$ (Meier et al., 2000 ) or $1 \mu \mathrm{g} / \mathrm{ml}$ (present study)]. If the antibody was responsible for cluster formation, then cluster size would vary greatly as a function of antibody concentration. The surface areas that have been measured correspond to equivalent disks of $\sim 0.36 \mu \mathrm{m}$ in diameter, a value above the theoretical optical resolution of our microscope $(100 \times$ objective, numerical aperture 1.4 at $500 \mathrm{~nm})$ : 
Figure 3. Features of cell surface GlyR clusters during the restoration phase. Neurons were treated as in Figure 2. A, Relationships of cellsurface clusters of GlyR myc-Thr:: $\alpha 1$ subunits to VIAAT immunoreactivity. Cell surface c-myc (red) and VIAAT ( green) immunofluorescences are shown superimposed, at high enlargement (thus pixelized), in cells fixed at 30 min of the restoration phase. Arrowheads, Nonsynaptic myc immunoreactivity; arrows, examples of myc/VIAAT colocalization. $B$, Surface area of myc-tagged GlyR clusters. The surface area of peripheral clusters present on soma and dendrites was determined using NIH version 1.52 software at the indicated time point. Measured sizes did not differ significantly, and the surface area could be averaged to $0.11 \pm 0.01$ $\mathrm{mm}^{2}$ (SEM; $\left.n=120\right)$ during the restoration phase. $C$, Absence of association of newly inserted myc-tagged GlyR with clusters inserted in the plasma membrane before thrombin treatment. Neurons were cotransfected with
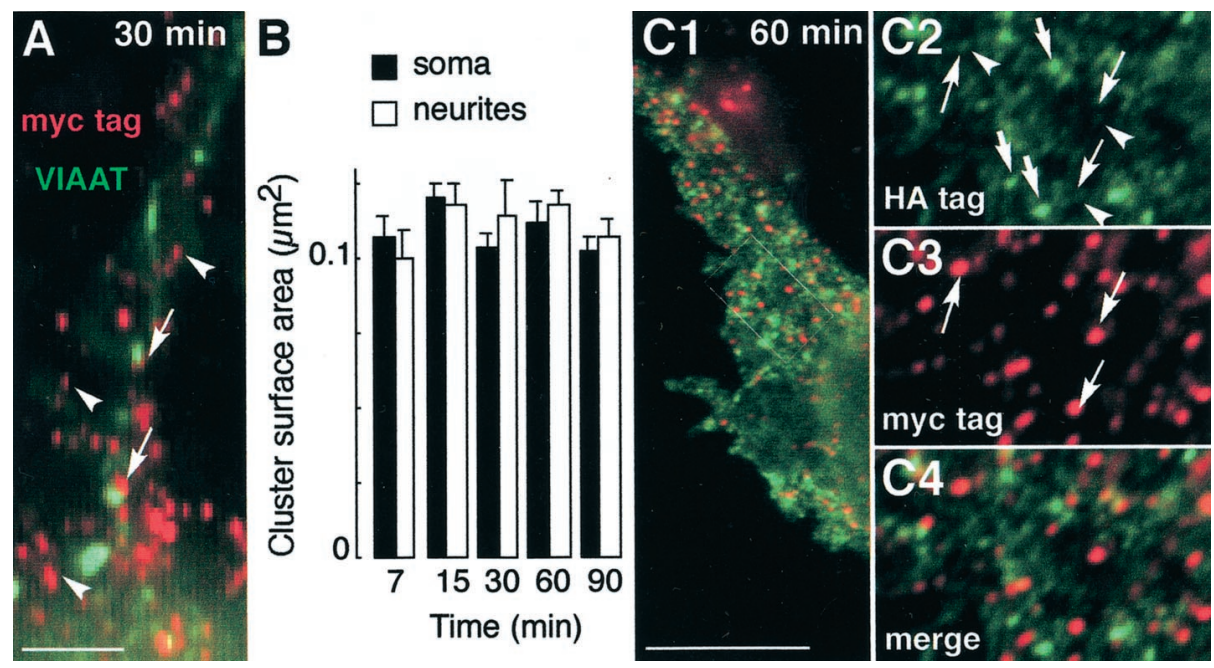

pC-HA:: $\alpha 1$ and pC-myc-Thr:: $\alpha 1$ and processed as described in Figure 2. Cell surface double immunofluorescence staining of c-myc (red) and HA (green) tags was performed after $60 \mathrm{~min}$, as indicated in Materials and Methods. Superimposition of both labels is shown in C1 and C4, and $\mathrm{HA}$ and c-myc-selective labeling is shown in $C 2$ and $C 3$, respectively. $C 2-C 4$, Higher magnification of regions outlined in $C 1$. Note the relatively low HA staining (arrowheads) in clusters of myc-tagged $\alpha 1$ subunit (arrows) in comparison with that of HA-positive, myc-negative clusters (thick arrows). Scale bars: $A$, $1 \mu \mathrm{m} ; C 1,10 \mu \mathrm{m}$.

$0.22 \mathrm{~nm}$. Our measurements are certainly biased at the low end by diffraction effects for clusters smaller than the optical resolution. Yet this bias does not modify our conclusion that the size of nonsynaptic clusters did not increase from their time of appearance until $90 \mathrm{~min}$ of restoration. This size invariance raised the following question. Did the myc-tagged $\alpha 1$ clusters originate from the association of new receptors with pre-existing, trimmed $\alpha 1$ clusters, or did they form independently of them? To address this point, the restoration phase was analyzed in neurons transfected with equimolar amounts of pC-HA:: $\alpha 1$ and pC-myc-Thr:: $\alpha 1$. After a $1 \mathrm{hr}$ restoration, clusters of two types existed at the cell surface, respectively bearing HA tag only or both HA and myc tags (Fig. 3C1-C4). The latter clusters were expected because most newly inserted GlyR is likely homomeric (Meier et al., 2000) and randomly composed of myc- and HA-tagged $\alpha 1$ subunits. These newly inserted clusters, which could be clearly identified by their myc tag staining (Fig. 3C3), exhibited a lower HA tag staining as compared with pre-existing ones bearing the HA tag only (Fig. 3C2). Very likely, lower anti-HA antibody binding arose from steric hindrance revealed in this particular case in which primary antibodies compete for topologically equivalent antigenic sites. An important finding of this experiment lies in the fact that newly inserted myc-labeled GlyR did not associate with the bright (pre-existing) clusters exclusively labeled with the HA tag (Fig. 3C4). If pre-existing HA-tagged clusters did not recruit newly inserted myc-labeled GlyR, then one could predict that their number was almost invariant during the 60 min restoration phase studied. Yet the average density of HA-positive, mycnegative GlyR clusters did not decrease from the onset $(4.2 \pm 0.2$ clusters $\left./ \mu \mathrm{m}^{2} ; n=5\right)$ to time $60 \min \left(5.1 \pm 0.2\right.$ clusters $/ \mu \mathrm{m}^{2} ; n=$ $5)$ of the restoration phase. This result favors the notion that newly inserted myc-tagged GlyR did not populate clusters already containing receptors. The above results also argue against an antibody-dependent formation of receptor clusters in neurons. If the antibody induces receptor aggregation, (1) the size of the clusters would be a function of the increasing cell surface GlyR concentration during the restoration phase and (2) the anti-HA antibody would induce the fusion of pre-existing and newly in- serted receptors that both possess the HA tag. As a consequence, the formation of receptor clusters in transfected neurons does not result from a progressive, time-dependent association of newly inserted molecules. Together with the invariance of cluster surface area, this shows that aggregation of receptors is not a concentration-dependent process.

Altogether, these experiments indicate that newly synthesized GlyR myc-Thr: $\alpha 1$ is inserted in the plasma membrane at nonsynaptic loci already forming small, discrete clusters.

\section{Exocytosis of newly synthesized GlyR occurs in the somatic and proximal dendritic plasma membrane}

The early insertion of GlyR at the cell surface was always observed on the soma and proximal dendritic segments. This suggested that the exocytosis of newly synthesized GlyR did not occur randomly over the somatic and dendritic compartments. To test this hypothesis, the kinetics of GlyR transport to the cell surface was scored by counting receptor clusters present in the somatic and dendritic plasma membrane at various stages after the release of the temperature block and for up to $90 \mathrm{~min}$. This was allowed by the invariant size of cell surface clusters during the restoration phase. The replenishment of the somatic and dendritic pools of receptors displayed distinct time courses (Fig. $4 A$ ). The transport of GlyR to the somatic surface was a biphasic process. The initial and steep phase of the curve terminated $\sim 30$ min after the $37^{\circ} \mathrm{C}$ shift. It likely corresponded to the nearly synchronized transport of receptors previously sequestered in the TGN (Griffiths et al., 1985) and delivered with a half-time of $\sim 15$ min. This was followed by a much slower transport phase. This reflected the steady-state externalization rate of receptors synthesized during and after the temperature-induced block. These kinetics are exactly what was expected from this experimental strategy. In comparison, cell surface GlyR clusters over dendrites could be detected as early as 5-7 min and increased steadily over the investigated $90 \mathrm{~min}$ restoration phase. In dendrites, a rapid phase that would reflect the synchronized wave of GlyR transport could not be detected. This indicated that replenishment of cell 

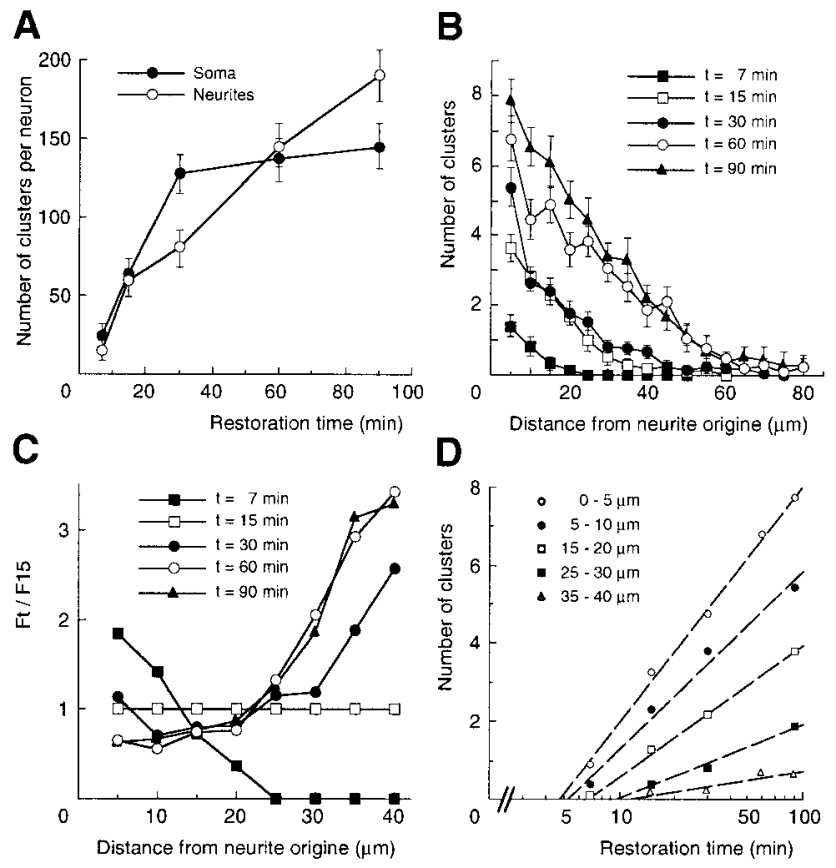

Figure 4. Quantitative analysis during the restoration phase. The mean number of cell surface myc-tagged GlyR clusters ( \pm SEM) from two separate experiments was determined from 7 to 90 min after the 19.5$37^{\circ} \mathrm{C}$ shift. $A$, Kinetics of cluster accumulation in somatic and dendritic compartments (at least 8 neurons per time point). $B$, Comparison of cluster numbers in dendrites as a function of distance to soma. Plots of the counts obtained for $5 \mu \mathrm{m}$ length intervals on dendrites $(n>40)$ at the indicated recovery time. $C$, Relative distributions of clusters. Relative frequency $F_{\mathrm{t}} / F_{15}$ over dendrite length is calculated as the ratio of frequency at time $t\left(F_{\mathrm{t}} ; t=7,15,30,60\right.$, and $\left.90 \mathrm{~min}\right)$ to frequency at $15 \mathrm{~min}$ $\left(F_{15}\right) \cdot t=15 \mathrm{~min}$ is the half time for GlyR delivery from TGN (see Results). $D$, Kinetics of GlyR replenishment in dendrites at various distances (as indicated) from the soma. Counts at each distance (spatial bin $=5 \mu \mathrm{m})$ are plotted on a logarithmic time scale. $A-D$ are from the same set of neurons.

surface GlyR populations in soma and dendrites, respectively, involved distinct pathways.

The delivery of GlyR to dendrites was quantified more precisely by measuring the distribution of clusters over individual dendrites at the same time points of the restoration phase as above. The recovery of cell surface GlyR expression was not homogenous in dendrites: at all stages of the restoration the density of clusters per $5 \mu \mathrm{m}$ length intervals decreased from proximal to distal dendritic ends (Fig. 4B). After $7 \mathrm{~min}$, all dendritic GlyR clusters were localized within $20 \mu \mathrm{m}$ of the cell body, whereas at $60 \mathrm{~min}$, GlyR clusters were found as far as 80 $\mu \mathrm{m}$. This indicated that dendrites were progressively populated by the receptor released by the somatic TGN at the onset of the restoration phase. However, the analysis of the frequency of receptor occurrence along dendrites showed that it varied with the time elapsed after warmup, the frequency within the proximal $15-20 \mu \mathrm{m}$ diminishing substantially while increasing in distal segments. This is particularly illustrated by the curves obtained for the relative frequencies (Fig. $4 C$ ) calculated as the ratio of frequency at time t to that at $15 \mathrm{~min}$, the time corresponding to half delivery from the TGN (Fig. 4A). The negative to positive transition in the curve slope from time points taken before and after $15 \mathrm{~min}$, respectively, indicated that GlyR clusters did not insert randomly in dendrites. A random GlyR insertion-exocytosis, arising from fusion events occurring evenly over the entire dendritic plasma membrane, would give horizontal relative frequency curves (with 1 as ordinate). Therefore, the curves obtained here may reflect two distinct processes taking place during the restoration phase: either a shift from an early preferentially proximal to a late preferentially distal exocytosis, or the redistribution of surface GlyR from proximal to distal dendritic segments.

Together, these results indicate that newly synthesized GlyR delivered from the TGN (1) undergoes early exocytosis in the cell body and the initial portions of dendrites and suggests that (2) it is subsequently delivered to distal regions of the dendrites.

\section{Cell surface redistribution of newly synthesized GlyR to distal dendrites}

We next investigated the question of how GlyR clusters occur in more distal portion of dendrites. Because GlyR clusters appeared concomitantly with, or immediately after, exocytosis, it could be assumed that transport containers of the exocytic pathway contained enough receptor to allow their visualization, as observed in COS-7 cells. Moreover, as shown in Figure 4 $A$, the number of GlyR clusters delivered to dendrites within $60 \mathrm{~min}$ is close to that present at the surface of the soma (130-140 cluster per cell). Therefore, after $60 \mathrm{~min}$, the presence of a fraction of the corresponding intracellular containers, if any, was expected to be detected in dendrites within $60 \mu \mathrm{m}$ of soma (Fig. $4 B$ ). The restoration phase was therefore initiated in cells processed as in Figure 2 and followed by a second thrombin digestion before fixation (as in Fig. 1D). No cell surface myc-epitope labeling was observed on living cells after the second thrombin treatment (data not shown), indicating that the removal of the tags when performed at the end of a restoration phase was as efficient as in the first treatment (Figs. 1C2,D2, 2A). This allowed the selective visualization of intracellular myc-tagged GlyR protected during the last thrombin digestion. Surprisingly, under these conditions, no significant intracellular labeling (corresponding to internalized receptors) could be detected in dendrites at the end of the $19.5^{\circ} \mathrm{C}$ step. Only somatic and perinuclear myc antigenicity could be seen at the onset of the restoration phase; mainly outlining TGN and to some extent late endosomal cisternae (Fig. 5A2, time 0 of the restoration phase). Later, although myc-tagged GlyR leaving the TGN could be detected in the soma, no staining of the myc epitope could be observed in dendrites at either early or late restoration times. The distribution of intracellular myc tag shown after $60 \mathrm{~min}$ is representative of all stages of the restoration phase (Fig. 5B2). This indicated that in these experiments, intracellular transport of newly synthesized GlyR in dendrites was not a predominant pathway. As a consequence, replenishment of the dendritic pool of GlyR mainly, if not totally, occurred via redistribution by diffusion of initially somatic cell surface clusters.

Given the redistribution of GlyR clusters from a somatic pool to a dendritic one, the appearance of dendritic clusters could be postulated to follow first-order kinetics. Numbers of clusters over time were thus determined at various positions over dendrites up to $40 \mu \mathrm{m}$ from soma. Linear restoration curves were obtained by plotting cluster numbers on a logarithmic time scale (Fig. 4D). Using the time obtained from the curves to reach a defined position, the average linear velocity of GlyR clusters in dendrites was calculated as $3.3 \mu \mathrm{m} / \mathrm{min}$. The apparent diff usion coefficient D, was calculated by applying Fick's second law:

$$
\left(\frac{\delta n}{\delta t}\right)_{x}=D\left(\frac{\delta^{2} n}{\delta x^{2}}\right)_{t}
$$



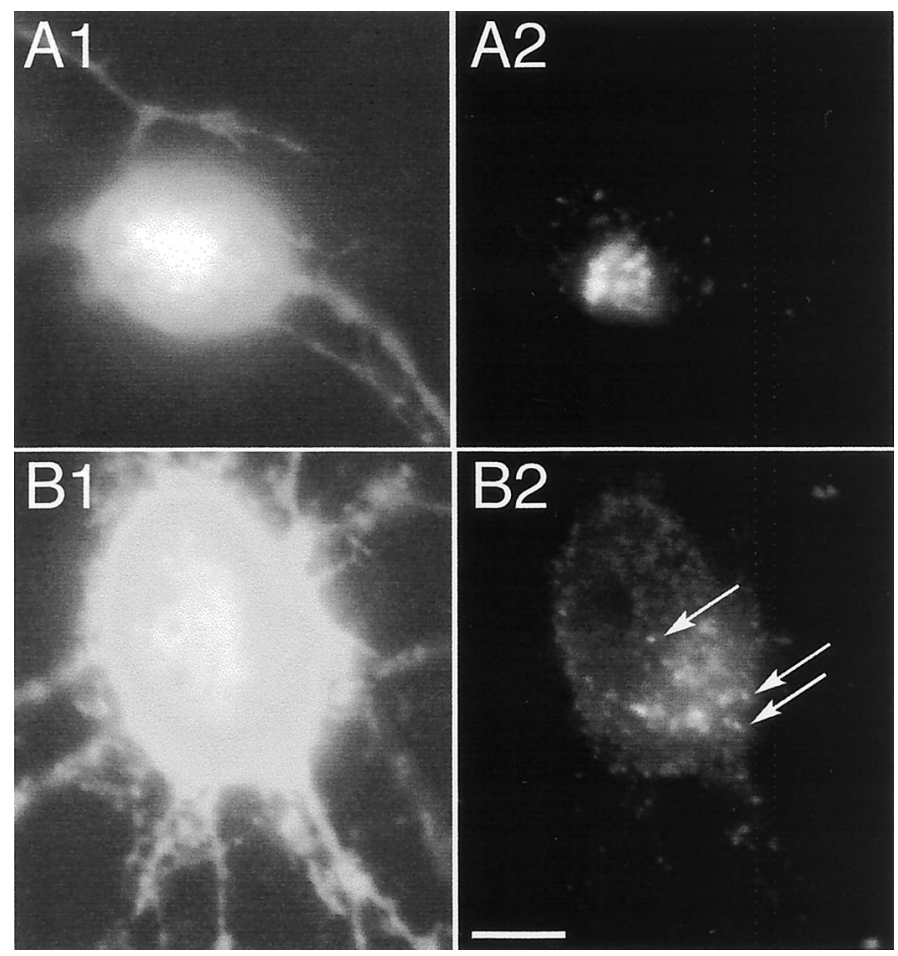

Figure 5. Redistribution of intracellular myc-tagged GlyR during the restoration phase. Cells were cotransfected with pC-myc-Thr:: $\alpha 1$ and pEGFP-N1. The c-myc epitope was revealed as in Figure $2 B$ by immunostaining of cells after a second thrombin treatment then fixed and permeabilized at $0(A 1, A 2)$ and $60(B 1, B 2)$ min after the $19.5-37^{\circ} \mathrm{C}$ shift. $A 1, B 1$, GFP fluorescence; $A 2, B 2$, c-myc immunoreactivity. Note the appearance of putative transport containers (arrows) in B2. Scale bar, $10 \mu \mathrm{m}$.

assuming a constant dendritic section, using $n$ as the number of clusters per $5 \mu \mathrm{m}$ length interval at increasing distances $(x)$ from soma and at various times $(t)$ of the restoration phase. $D$ computed from the data of Figure 4, $B$ and $D$, was found to be $2.76 \times$ $10^{-2} \pm 1.7 \times 10^{-2} \mu \mathrm{m}^{2} / \mathrm{sec}($ mean \pm SEM), a value close to the diffusion coefficient that we obtained using optical tracking of GlyR in transfected neurons $\left(2.81 \times 10^{-2} \pm 7 \times 10^{-3} \mu \mathrm{m}^{2} / \mathrm{sec}\right)$ (Meier et al., 2001). Although an approximation of the GlyR redistribution process, these results are consistent with the notion that dendritic clusters arise from initially somatic or more proximal ones by diffusion.

Altogether, these results indicate that (1) the intracellular route for GlyR delivery to dendrites is a minor pathway and (2) dendritic localization is mainly achieved by cell surface diffusion of receptor initially inserted in the somatic compartment.

\section{DISCUSSION}

We analyzed in cultured neurons the export of newly synthesized GlyR from the TGN to the plasma membrane, to define its exocytosis site. The basis of this study is the observation that exogenous GlyR is gradually positioned into gephyrin-enriched postsynaptic domains over the neuronal somatodendritic surface (Meier et al., 2000). We therefore postulated that the mechanisms required for proper targeting of GlyR were not saturated in the experiments performed here in neurons exhibiting intensive synaptogenesis (Béchade et al., 1996).

Our strategy was to transfect cells with a recombinant GlyR subunit bearing an exocytoplasmic, proteolytically cleavable tag. Two combined mild treatments created an observable synchro- nized exocytic wave: (1) a transient, reversible block of exit from the TGN (Matlin and Simons, 1983; Griffiths et al., 1985; Hughson et al., 1988) and (2) a selective removal of extracytoplasmic tags using thrombin digestion. The restoration of cell surface expression of the tag, corresponding to the resumption of post-Golgi transport, was monitored by immunofluorescence microscopy.

\section{Newly synthesized GlyR diffuses as clusters from somatic to dendritic compartments}

We show that exocytosis of newly synthesized GlyR mainly occurs at nonsynaptic sites in the cell body and the initial portion of dendrites followed by receptor diffusion to distal regions of the dendritic plasma membrane. Different time courses characterize the appearance of GlyR in the somatic and dendritic areas. Because a wave of vesicular transport was created between the Golgi complex and the plasma membrane (Griffiths et al., 1985), a two-phase process should account for the recovery of cell surface GlyR over the entire somatodendritic compartment. This is not the case, indicating that somatic and dendritic domains are not equivalent sites for the rapid and early delivery of exocytic carriers of GlyR. Therefore, we conclude that, because of the lack of detectable transient intracellular flow of transport containers in dendrites, the somatic membrane (and to some extent the initial dendritic segment) is the major acceptor for exocytic fusion.

Our results show that GlyR subsequently populates dendrites, in a phase during which no association with synapses was noted, via diffusion of a receptor pool initially located in the soma. Interestingly, the analysis of GlyR distributions in dendrites as a function of time revealed first-order kinetics, reinforcing the idea of a precursor-product relationship between somatic and dendritic GlyR molecules. This transition is characterized by a diffusion coefficient close to that obtained by single particle tracking in transfected neurons (Meier et al., 2001) and to those of other diff usive membrane proteins (Saxton, 1997; Saxton and Jacobson, 1997; Kusumi, 1999).

A striking feature of homomeric GlyR expressed in neurons is its ability to form minute clusters independently of detectable interaction with gephyrin (Meier et al., 2000). However, GlyR was shown to progressively populate plasma membrane postsynaptic domains where it colocalizes with endogenous gephyrin (Meier et al., 2000). The present results show that these clusters form very early after arrival of GlyR in the plasma membrane. Their almost uniform size does not vary with time, although the overall concentration of receptor molecules at the cell surface increases, suggesting that they form stable GlyR assemblies that do not undergo aggregation via a concentration-dependent process. This is confirmed by the observation that newly synthesized GlyR was not associated with clusters that had been inserted in the plasma membrane before the temperature-induced arrest in the TGN. Our previous results combined with those presented here indicate that extrasynaptic minute GlyR clusters represent true kinetic intermediates between newly synthesized and postsynaptic GlyR.

Whether these complexes form before or after exocytosis of transport carriers is unknown. Neuron-specific properties of GlyR may govern its clustering (Meier et al., 2000). This may include (1) lateral or vertical interaction with proteins triggering the formation of stable receptor-enriched domains and (2) posttranslational modifications allowing either recognition of partner proteins or homophilic interactions. With regard to the participation of cytoplasmic proteins, this event could take place as early as the Golgi complex. Indeed, the spectrin- or ankyrin-based 
Golgi-associated membrane skeleton very likely promotes the formation of protein microdomains within the TGN, while contributing to vesicle transport (Beck and Nelson, 1996; Devarajan et al., 1996; Beck et al., 1997). However, homophilic association would be analogous to the kin recognition phenomenon applying to Golgi enzymes (Nilsson et al., 1994).

\section{Implications for GlyR targeting in neurons}

As previously proposed (Craig et al., 1994), accumulation of receptors in synapses may result from a unspecified fusion of post-Golgi vesicles with the plasma membrane where receptors could diffuse before retention in postsynaptic sites. Another mechanism would correspond to the direct targeting via specific transport vesicles after sorting in the TGN. Our present and previous (Meier et al., 2000) results show that GlyR at the time of, or shortly after, plasma membrane insertion is not found in axons and not associated with synapses. Instead, the present work shows that it can diffuse from proximal to distal dendritic regions, indicating that it is not stabilized at a specific locus. Moreover, we showed that it can nevertheless be incorporated into synapses (Meier et al., 2000). Altogether, our data strongly suggest that GlyR is routed to synapses via the first mechanism. This implies that two types of targeting information are required: one for sorting into vesicles destined for the somatic plasma membrane and another for retention in postsynaptic domains. As a consequence, GlyR is not necessarily segregated in the TGN from other somatodendritic proteins. Whether this diffusion-retention model holds for the targeting of other dendritic receptors will require further investigations. A plausible prediction of the model would be that several distinct molecules, including other receptors, are transported in GlyR-containing transport carriers. A diffusion-retention model posits that vesicular traffic is not vectorial. Because GlyR never appeared in axons, it raises another question: is GlyR vectorially transported to the somatodendritic domain?

The vectorial transport pathway, first described in polarized cells for the construction of apical and basolateral domains, either begins with the formation of Golgi-derived transport vesicles segregating specific proteins (Rodriguez-Boulan and Nelson, 1989; Keller and Simons, 1997), or involves a transcytosis step with endosomal sorting if proteins are first delivered to a distinct plasma membrane domain (Bartles et al., 1987; Matter et al., 1990). These pathways also account for neuron polarization (Winckler and Mellman, 1999). Examples of direct routing of somatodendritic proteins sorted in the TGN, and excluded from axons, are provided by the polymeric Ig (de Hoop et al., 1995), the transferrin (West et al., 1997), the low-density lipoprotein (Jareb and Banker, 1998) receptors, and the GLYT1 isoform of the glycine transporter (Poyatos et al., 2000). Signals responsible for vectorial transport were also proposed for the neurotransmitter receptors mGluR2 (Stowell and Craig, 1999) and GluR1 (Ruberti et al., 2000). Plausibly, such signals, still to be identified, would also exist in GlyR leading to exclusion from axons because, as is the case for the above proteins when overexpressed in neurons, in our present or previous work GlyR was never expressed in axons (Meier et al., 2000). GlyR targeting, using two types of sorting information, would thus be similar to that of prominin, which is enriched in apical microvillar subdomains of epithelial cells (Corbeil et al., 1999). Surprisingly, however, exocytosis of GlyR did not occur significantly in dendrites (although synapses are also located in this compartment). This distinguishes its insertion-retention process from those of other selec- tively retained proteins: the $\mathrm{Na}^{+} / \mathrm{K}^{+}$-ATPase (Hammerton et al., 1991; Mays et al., 1995a,b) and the $\alpha 2 \mathrm{~B}$-adrenergic receptor (Wozniak and Limbird, 1996).

The lack of vesicular transport of GlyR in distal regions of dendrites is consistent with the notion that the specific retention of an otherwise diffusive protein is sufficient for synaptic localization without any intracellular routing over long distances. The diffusion-retention model proposed for GlyR thus points to the key role of the retention signal and in turn to the anchoring role of gephyrin. It remains to be investigated whether a diffusionretention process can be extrapolated to other synapses or ion channel-enriched domains (Scannevin et al., 1996; Zhou et al., 1998). This mechanism has already been proposed for the neuromuscular junction, because diffusing, mobile acetylcholine receptors are progressively inserted and stabilized at postsynaptic loci during synaptogenesis by the anchoring protein rapsyn $(\mathrm{Ku}-$ romi et al., 1985; Froehner, 1993). The assemblies of cytoplasmic and transmembrane proteins found in inhibitory (Kirsch, 1999; Kneussel and Betz, 2000, see references) and excitatory (Kim and Huganir, 1999, see references) synapses would constitute multivalent binding sites recruiting receptors within postsynaptic loci. On the one hand, their availability and saturation, not required for initial targeting, would control the rate-limiting step of postsynaptic capture. This hypothesis is supported by the observation that dendritically delivered receptors are not always clustered in synapses (Stowell and Craig, 1999; Ruberti and Dotti, 2000). On the other hand, receptor tethering could likely be controlled at the level of the plasma membrane and not at the exocytosis step (as in the direct targeting model). This could be achieved by acting on an equilibrium between diffusive and immobilized receptor molecules. Such a hypothesis is favored by the demonstration that cell surface GlyR can rapidly alternate between diffusive and confined states, the frequency of the latter being increased by gephyrin (Meier et al., 2001).

\section{REFERENCES}

Bartles JR, Feracci HM, Stieger B, Hubbard AL (1987) Biogenesis of the rat hepatocyte plasma membrane in vivo: comparison of the pathways taken by apical and basolateral proteins using subcellular fractionation. J Cell Biol 105:1241-1251.

Béchade C, Colin I, Kirsch J, Betz H, Triller A (1996) Expression of glycine receptor a subunits and gephyrin in cultured spinal neurons. Eur J Neurosci 8:429-435.

Beck KA, Nelson WJ (1996) The spectrin-based membrane skeleton as a membrane protein-sorting machine. Am J Physiol 270:C1263-C1270.

Beck KA, Buchanan JA, Nelson WJ (1997) Golgi membrane skeleton: identification, localization and oligomerization of a $195 \mathrm{kDa}$ ankyrin isoform associated with the Golgi complex. J Cell Sci 110:1239-1249.

Brewer GJ, Torricelli JR, Evege EK, Price PJ (1993) Optimized survival of hippocampal neurons in B27-supplemented Neurobasal, a new serum-free medium combination. J Neurosci Res 35:567-576.

Burack MA, Silverman MA, Banker G (2000) The role of selective transport in neuronal protein sorting. Neuron 26:465-472.

Colin I, Rostaing P, Augustin A, Triller A (1998) Localization of components of glycinergic synapses during rat spinal cord development. J Comp Neurol 398:359-372.

Corbeil D, Roper K, Hannah MJ, Hellwig A, Huttner WB (1999) Selective localization of the polytopic membrane protein prominin in microvilli of epithelial cells-a combination of apical sorting and retention in plasma membrane protrusions. J Cell Sci 112:1023-1033.

Craig AM, Blackstone CD, Huganir RL, Banker G (1994) Selective clustering of glutamate and gamma-aminobutyric acid receptors opposite terminals releasing the corresponding neurotransmitters. Proc Natl Acad Sci USA 91:12373-12377.

de Hoop M, von Poser C, Lange C, Ikonen E, Hunziker W, Dotti CG (1995) Intracellular routing of wild-type and mutated polymeric immunoglobulin receptor in hippocampal neurons in culture. J Cell Biol 130:1447-1459

Devarajan P, Stabach PR, Mann AS, Ardito T, Kashgarian M, Morrow JS (1996) Identification of a small cytoplasmic ankyrin (AnkG119) in the kidney and muscle that binds beta I sigma spectrin and associates with the Golgi apparatus. J Cell Biol 133:819-830. 
Dumoulin A, Rostaing P, Bedet C, Levi S, Isambert MF, Henry JP, Triller A, Gasnier B (1999) Presence of the vesicular inhibitory amino acid transporter in GABAergic and glycinergic synaptic terminal boutons. J Cell Sci 112:811-823.

Essrich C, Lorez M, Benson JA, Fritschy JM, Luscher B (1998) Postsynaptic clustering of major GABAA receptor subtypes requires the gamma 2 subunit and gephyrin. Nat Neurosci 1:563-571.

Fanning AS, Anderson JM (1999) Protein modules as organizers of membrane structure. Curr Opin Cell Biol 11: 432-439.

Feng G, Tintrup H, Kirsch J, Nichol MC, Kuhse J, Betz H, Sanes JR (1998) Dual requirement for gephyrin in glycine receptor clustering and molybdoenzyme activity. Science 282:1321-1324.

Froehner SC (1993) Regulation of ion channel distribution at synapses. Annu Rev Neurosci 16:347-368.

Gardiol A, Racca C, Triller A (1999) Dendritic and postsynaptic protein synthetic machinery. J Neurosci 19:168-179.

Gardiol A, Racca C, Triller A (2001) RNA transport and local protein synthesis in the dendritic compartment. Results Probl Cell Differ 34, in press.

Garner CC, Nash J, Huganir RL (2000) PDZ domains in synapse assembly and signalling. Trends Cell Biol 10:274-280.

Griffiths G, Pfeiffer S, Simons K, Matlin K (1985) Exit of newly synthesized membrane proteins from the trans cisterna of the Golgi complex to the plasma membrane. J Cell Biol 101:949-964.

Hammerton RW, Krzeminski KA, Mays RW, Ryan TA, Wollner DA, Nelson WJ (1991) Mechanism for regulating cell surface distribution of $\mathrm{Na}+, \mathrm{K}(+)$-ATPase in polarized epithelial cells. Science 254:847-850.

Hughson E, Wandinger-Ness A, Gausepohl H, Griffiths G, Simons K (1988) The cell biology of enveloped virus infection of epithelial tissues. In: Centenary symposium of the Pasteur Institute, (Schwartz M, ed), pp 75-89. Paris: Elsevier.

Jareb M, Banker G (1998) The polarized sorting of membrane proteins expressed in cultured hippocampal neurons using viral vectors. Neuron 20:855-867.

Keller P, Simons K (1997) Post-Golgi biosynthetic trafficking. J Cell Sci 110:3001-3009.

Kim JH, Huganir RL (1999) Organization and regulation of proteins at synapses. Curr Opin Cell Biol [Erratum (1999) 11:407-408] 11:248-254.

Kirsch J (1999) Assembly of signaling machinery at the postsynaptic membrane. Curr Opin Neurobiol 9:329-335.

Kirsch J, Langosch D, Prior P, Littauer UZ, Schmitt B, Betz H (1991) The 93-kDa glycine receptor-associated protein binds to tubulin. J Biol Chem 266:22242-22245.

Kirsch J, Wolters I, Triller A, Betz H (1993) Gephyrin antisense oligonucleotides prevent glycine receptor clustering in spinal neurons. Nature 366:745-748.

Kneussel M, Betz H (2000) Clustering of inhibitory neurotransmitter receptors at developing postsynaptic sites: the membrane activation model. Trends Neurosci 23:429-435.

Kneussel M, Brandstatter JH, Laube B, Stahl S, Muller U, Betz H (1999) Loss of postsynaptic GABA(A) receptor clustering in gephyrindeficient mice. J Neurosci 19:9289-9297.

Kuromi H, Brass B, Kidokoro Y (1985) Formation of acetylcholine receptor clusters at neuromuscular junction in Xenopus cultures. Dev Biol 109:165-176.

Kusumi A, Suzuki K, Koyasako K (1999) Mobility and cytoskeletal interactions of cell adhesion receptors. Curr Opin Cell Biol 11: 582-590.

Lévi S, Chesnoy-Marchais D, Sieghart W, Triller A (1999) Synaptic control of glycine and GABA(A) receptors and gephyrin expression in cultured motoneurons. J Neurosci 19:7434-7449.

Matlin KS, Simons K (1983) Reduced temperature prevents transfer of a membrane glycoprotein to the cell surface but does not prevent terminal glycosylation. Cell 34:233-243.

Matter K, Brauchbar M, Bucher K, Hauri HP (1990) Sorting of endogenous plasma membrane proteins occurs from two sites in cultured human intestinal epithelial cells (Caco-2). Cell 60:429-437.

Mays RW, Siemers KA, Fritz BA, Lowe AW, van Meer G, Nelson WJ (1995a) Hierarchy of mechanisms involved in generating $\mathrm{Na} / \mathrm{K}-$ ATPase polarity in MDCK epithelial cells. J Cell Biol 130:1105-1115.

Mays RW, Nelson WJ, Marrs JA (1995b) Generation of epithelial cell polarity: roles for protein trafficking, membrane-cytoskeleton, and E-cadherin-mediated cell adhesion. Cold Spring Harb Symp Quant Biol 60:763-773.

Meier J, Meunier-Durmort C, Forest C, Triller A, Vannier C (2000) Formation of glycine receptor clusters and their accumulation at synapses. J Cell Sci 113:2783-2795.

Meier J, Vannier C, Sergé A, Triller A, Choquet D (2001) Fast and reversible trapping of surface glycine receptors by gephyrin. Nat Neurosci 4:253-260.

Meyer G, Kirsch J, Betz H, Langosch D (1995) Identification of a gephyrin binding motif on the glycine receptor beta subunit. Neuron 15:563-572.

Misek DE, Bard E, Rodriquez-Boulan E (1984) Biogenesis of epithelial cell polarity: intracellular sorting and vectorial exocytosis of an apical plasma membrane glycoprotein. Cell 39:537-546.

Nilsson T, Hoe MH, Slusarewicz P, Rabouille C, Watson R, Hunte F, Watzele G, Berger EG, Warren G (1994) Kin recognition between medial Golgi enzymes in HeLa cells. EMBO J 13:562-574.

Pfeiffer F, Simler R, Grenningloh G, Betz H (1984) Monoclonal antibodies and peptide mapping reveal structural similarities between the subunits of the glycine receptor of rat spinal cord. Proc Natl Acad Sci USA 81:7224-7227.

Pfeiffer S, Fuller SD, Simons KJ (1985) Intracellular sorting and basolateral appearance of the $G$ protein of vesicular stomatitis virus in Madin-Darby canine kidney cells. J Cell Biol 101:470-476.

Poyatos I, Ruberti F, Martinez-Maza R, Gimenez C, Dotti CG, Zafra F (2000) Polarized distribution of glycine transporter isoforms in epithelial and neuronal cells. Mol Cell Neurosci 15:99-111.

Racca C, Gardiol A, Triller A (1997) Dendritic and postsynaptic localizations of glycine receptor alpha subunit mRNAs. J Neurosci 17:1691-1700.

Rodriguez-Boulan E, Nelson WJ (1989) Morphogenesis of the polarized epithelial cell phenotype. Science 245:718-725.

Ruberti F, Dotti CG (2000) Involvement of the proximal C terminus of the AMPA receptor subunit GluR1 in dendritic sorting. J Neurosci 20:RC78.

Saxton MJ (1997) Single-particle tracking: the distribution of diffusion coefficients. Biophys J 72:1744-1753.

Saxton MJ, Jacobson K (1997) Single-particle tracking: applications to membrane dynamics. Annu Rev Biophys Biomol Struct 26:373-399.

Scannevin RH, Murakoshi H, Rhodes KJ, Trimmer JS (1996) Identification of a cytoplasmic domain important in the polarized expression and clustering of the Kv2.1 K+ channel. J Cell Biol 135:1619-1632.

Stowell JN, Craig AM (1999) Axon/dendrite targeting of metabotropic glutamate receptors by their cytoplasmic carboxy-terminal domains. Neuron 22:525-536.

Triller A, Cluzeaud F, Pfeiffer F, Betz H, Korn H (1985) Distribution of glycine receptors at central synapses: an immunoelectron microscopy study. J Cell Biol 101:683-688.

Triller A, Cluzeaud F, Korn H (1987) gamma-Aminobutyric acidcontaining terminals can be apposed to glycine receptors at central synapses. J Cell Biol 104:947-956.

Vannier C, Triller A (1997) Biology of the postsynaptic glycine receptor. Int Rev Cytol 176:201-244.

West AE, Neve RL, Buckley KM (1997) Identification of a somatodendritic targeting signal in the cytoplasmic domain of the transferrin receptor. J Neurosci 17:6038-6047.

Winckler B, Mellman I (1999) Neuronal polarity: controlling the sorting and diffusion of membrane components. Neuron 23:637-640.

Wozniak M, Limbird LE (1996) The three alpha 2-adrenergic receptor subtypes achieve basolateral localization in Madin-Darby canine kidney II cells via different targeting mechanisms. J Biol Chem 271:5017-5024

Zhou D, Lambert S, Malen PL, Carpenter S, Boland LM, Bennett V (1998) AnkyrinG is required for clustering of voltage-gated Na channels at axon initial segments and for normal action potential firing. J Cell Biol 143:1295-1304. 